\title{
The differential impact of maternal dietary macronutrient composition on offspring birthweight - results from the Danish National Birth Cohort
}

\author{
S.S. Sharma ${ }^{1}$, D.C. Greenwood ${ }^{2}$, C. Granström ${ }^{4}$, N.A.B. Simpson ${ }^{3}$, S.F. Olsen ${ }^{4}$ and J.E. Cade ${ }^{1}$ \\ ${ }^{1}$ Nutritional Epidemiology Group, School of Food Science and Nutrition, University of Leeds, Leeds LS2 9JT, UK, \\ ${ }^{2}$ Division of Biostatistics, University of Leeds, Leeds LS2 9JT, UK, ${ }^{3}$ Division of Obstetrics and Gynaecology, \\ University of Leeds, Leeds LS2 9JT, UK and ${ }^{4}$ Centre for Fetal Programming, Department of Epidemiology Research, \\ Statens Serum Institut, Copenhagen, Denmark.
}

There is limited evidence about the differential impact of the dietary macronutrient composition (carbohydrate [CHO], protein and fat) during pregnancy on offspring birthweight ${ }^{(1,2)}$. The aim of our study was to explore the association between maternal dietary macronutrient intake in the second trimester and offspring birthweight.

The study included 63,755 mother-infant pairs within the Danish National Birth Cohort (DNBC) ${ }^{(3)}$ in Denmark. Dietary data was collected in the food frequency questionnaires (FFQs) around the $25^{\text {th }}$ week of gestation. Baseline information was collected from the participants at recruitment around the $12^{\text {th }}$ week of gestation. Multiple linear regression models analysed the association between maternal macronutrient dietary intake in the second trimester and changes in birthweight. Both macronutrient models were mutually adjusted for energy contributing macronutrients. Model 1 was adjusted for confounders including pre-pregnancy body mass index (BMI), alcohol intake, smoking, parity, physical activity, dietary supplements, and competing exposures including gestational age at delivery, and sex of the offspring, and Model 2 was further adjusted for total micronutrient intakes (diet plus supplement) including calcium, iron, folate and vitamin $\mathrm{B}_{12}$.

\begin{tabular}{|c|c|c|c|c|c|c|}
\hline \multirow{2}{*}{$\begin{array}{l}\text { Macronutrient }{ }^{1} \text { intake } \\
\text { (increment) } \\
\text { Trimester } 2 \mathrm{n}=63,755\end{array}$} & \multicolumn{3}{|c|}{ Birthweight (g), Model 1} & \multicolumn{3}{|c|}{ Birthweight (g), Model 2} \\
\hline & Birthweight $^{\mathrm{a}}$ & $95 \% \mathrm{CI}$ & $p$ value & Birthweight $^{\mathrm{b}}$ & $95 \% \mathrm{CI}$ & $p$ value \\
\hline Total energy $(600 \mathrm{kcal} / \mathrm{d})$ & 9 & 6 to 13 & $<0.001$ & 0.09 & -4 to 4 & $0 \cdot 960$ \\
\hline Carbohydrate $(100 \mathrm{~g} / \mathrm{d})$ & 16 & 10 to 23 & $<0 \cdot 001$ & 14 & 9 to 20 & $<0 \cdot 001$ \\
\hline Fat $(30 \mathrm{~g} / \mathrm{d})$ & -22 & -27 to -17 & $<0 \cdot 001$ & -23 & -27 to -18 & $<0.001$ \\
\hline Protein $(30 \mathrm{~g} / \mathrm{d})$ & 21 & 14 to 29 & $<0.001$ & 17 & -9 to 25 & $<0.001$ \\
\hline
\end{tabular}

${ }^{1}$ Mutually adjusted for other energy contributing macronutrients a Adjusted for pre-pregnancy body mass index (BMI), alcohol intake, smoking, parity, physical activity, dietary supplements, gestational age at delivery, and sex of the offspring ${ }^{\mathrm{b}}$ Additional adjustment for total micronutrient intakes (calcium, iron, folate and vitamin $\mathrm{B}_{12}$ ).

Results showed that each additional $100 \mathrm{~g} /$ day $\mathrm{CHO}$ and $30 \mathrm{~g} /$ day protein consumption in the second trimester were associated with higher birthweights of $14 \mathrm{~g}(95 \% \mathrm{CI} 9$ to 20 ; $\mathrm{P}<0.001)$ and $17 \mathrm{~g}(95 \% \mathrm{CI}-9$ to $25 ; \mathrm{P}<0.001)$ respectively. Conversely, each additional $30 \mathrm{~g} /$ day fat consumption was associated with a lower birthweight of $23 \mathrm{~g}(95 \% \mathrm{CI} 18$ to $27 ; \mathrm{P}<0 \cdot 001)$. CHO and protein intakes in the second trimester are associated with improving birthweight, whereas fat is associated with limiting offspring weight gain. We advise an appropriate balance of dietary energy intake during pregnancy to optimise birthweight.

1. Moore VM, Davies MJ, Willson KJ et al. (2004) J Nutr 134, 1820-1826.

2. Chong MF-F, Chia AR, Colega M et al. (2015) J Nutr 145, 1303-1310.

3. Olsen J, Melbye M, Olsen SF et al. (2001) Scand J Public Health 29, 300-307. 